difficult to focus on), but identification by shape alone is not sufficient.

Other crystals include recently injected corticosteroids, also cholesterol which is seen as flat plates. We have seen red/brown crystals from a haemarthrosis aspirate. These were identified as bilirubin. Occasionally crystals are seen which cannot be identified, and some of these may be the alternative crystal forms of calcium pyrophosphate, ${ }^{3}$ or of calcium phosphate.

\section{References}

1 Currey H L F, Vernon-Roberts B. Examination of synovial fluid. Clinics in Rheumatic Diseases 1976; 2: 149-77.
2 Dieppe P A, Crocker P R, Corke C F, Doyle D V, Huskisson E C, Willoughby D. Synovial fluid crystals. $Q J$ Med 1979; 48: 533-53.

3 Hearn P R, Russell R G G. Formation of calcium pyrophosphate crystals in vitro: implication for calcium pyrophosphate deposition diseases (pseudogout). Ann Rheum Dis 1980; 39: 222-7.

\title{
New methods for identification of crystalline material in joints
}

\author{
D. V. DOYLE AND P. R. CROCKER
}

From the Department of Rheumatology, St Bartholomew's Hospital, London EC1A $7 B E$

The identification of microcrystalline material in joint fluid and tissues by conventional electron microscopical (EM) methods requires about 48 hours' specimen preparation. We have developed a series of methods that, in the case of joint fluids, allows the rapid preparation of fresh specimens for EM examination and, in the case of tissue specimens, enables paraffin-embedded sections to be examined directly by scanning electron microscopy (SEM).

SYNOVIAL FLUIDS

(1) Cytocentrifugation.

Transmission electron microscopy (TEM) system. The fluid is cytocentrifuged onto coated EM grids, which are then examined by light microscopy (LM) to select the most suitable monolayer for examination by TEM. Crystalline material, where detected, is analysed by $x$-ray energy spectroscopy (XES).

Scanning electron microscopy (SEM) system. The fluid is cytocentrifuged onto a standard perspex slide $(7.6 \mathrm{~cm} / 2.5 \mathrm{~cm})$, which is then placed in the microscope for examination and analysis. The specimen on the perspex slide may also be microincinerated at low temperature to remove organic material, leaving crystals clearly exposed for examination.

Scanning electron microscopy with back-scattered electron imaging facility $(B E I)$. The specimen is prepared as for SEM, but the BEI facility enables rapid location of crystalline material by atomic number differences without the need for microincineration.

\section{(2) Millipore filtration.}

SEM system. Negative pressure filtration of synovial fluids is used to collect particulate material on the surface of a millipore filter. The filter is placed on a graphite stub in the bulk holder of the scanning electron microscope, and the surface examined by SEM and XES.

SEM system with BEI facility. The preparation is as for SEM, but the BEI facility enables rapid location of crystalline material.

\section{JOINT TISSUES}

Routine paraffin block sections are used. Standard $5 \mu \mathrm{m}$ sections are cut and mounted on perspex slides.

SEM system. The tissue section on the perspex slide is examined by light microscopy and the topography is noted. The section is then microincinerated at low temperature to expose particulate material for examination by SEM and XES.

$S E M$ system with $B E I$ facility. The preparation is as for SEM, but microincineration is unnecessary. Direct examination by BEI and XES is possible.

The identification of microcrystalline material in synovial fluid on articular tissue specimens by conventional EM methods is impractical for routine diagnostic use because it is extremely time consuming. The tissue specimen is cut into very small blocks, which must then be fixed, embedded, and sectioned. This procedure takes at least 48 hours and as the specimen blocks are very small and tissue deposits of crystals are often patchily distributed, the specimen selected for examination may well be devoid of crystalline material.

Our methods used standard laboratory fixation and preparation techniques. The specimens, apart from those involving millipore filtration, may be examined initially by light microscopy to determine whether EM examination is likely to be worthwhile. These techniques are a significant advance on traditional electron microscopical methods used for the detection of crystalline material in joint fluids and tissues. 